\title{
Tobacco Prevention \& Cessation - an effort that materializes the networking concept in tobacco control
}

\author{
Cornel Radu-Loghin ${ }^{1}$
}

Tobacco Prevention \& Cessation is launched at a time when the world is recognizing that the most effective policies are those based on scientific studies and solid evidence.

The European Network for Smoking and Tobacco Prevention (ENSP) is active since 1997 in tobacco control and for 18 years has played an important role in setting policies in this area at a European and international level ${ }^{1}$. Spearheading ENSP activities and projects are national representatives, organisations, academics, doctors, lawyers, health care professionals and activists who always worked together to fulfill the objectives and mission of ENSP. ENSP is the only truly pan-European network active in tobacco control being the key grassroots organization in implementing the World Health organization, Framework Convention on Tobacco Control (WHO-FCTG) at a European level. This was acknowledged by the WHO-FCTC - Conference of Parties during the session in Uruguay (November 2010) when ENSP received FCTC observer status ${ }^{2}$.

It is almost impossible to talk about FCTC in Europe without mentioning the involvement of at least one ENSP member. It is a collective effort particularly, an effort that materializes to an unprecedented level the networking concept. A network is not a list of organizations on a website to satisfy a condition of eligibility for European projects, a network is a group that acts in a consistent and coordinated way. Each node of the network adds value. This added scientific value will be found, from today, also, in the new journal, Tobacco Prevention \& Cessation. The novelty of this journal is the possibility offered to authors to send for evaluation manuscripts also written in their national language. This decision was taken by the General Assembly of the ENSP in response to the need for knowledge transfer among the tobacco control experts worldwide.
Backed by a strong editorial board with editors working in most European languages, Tobacco Prevention \& Cessation will be able to peer review and publish the most valuable scientific papers submitted in the authors proposed language and in languages of international circulation.

The gaps between the levels of tobacco control between countries are huge. We have both leading and lagging countries on tobacco control scales. Is it just to make such a ranking? What can motivate / demotivate countries? How important are the recommendations at an international level and how is this mediated by national political will? How to implement the FCTC and in particular Article 5.3? How are we to dismantle the tobacco industry myths? Are electronic cigarettes safer than regular cigarettes? These are examples of questions whose answers should have a solid scientific basis. It is a duty and a challenge for ENSP to provide answers, solutions and facts. Tobacco Prevention \& Cessation will provide the scientific basis for all this.

\section{REFERENCES}

1. European Network for Smoking and Tobacco prevention (ENSP). http://www.ensp.org/about (accessed 10 Oct 2015)

2. Conference of the Parties to theWHO Framework Convention on Tobacco Control FCTC/COP/4/ DIV/6. http://apps.who.int/gb/fctc/PDF/cop4/ FCTC_COP4_DIV6-en.pdf (accessed 10 Oct 2015)
AFFILIATION

1 Secretary General, European Network for Smoking and Tobacco Prevention (ENSP)

CORRESPONDENCE TO

Cornel Radu-Loghin European Network for Smoking and Tobacco Prevention, Chaussee d Ixelles 144, 1050 Brussels, Belgium Email: cornel.radu@ensp org 